\title{
The Potential Role of $\beta$-Hydroxy- $\beta$-Methylbutyrate (HMB) in the Management of Lean Body Mass Loss in Older Adults with Heart Failure and Cardiac Cachexia
}

Peter A McCullough ${ }^{1,2}$, Christina B Berberich ${ }^{3}$, Carolyn Alish ${ }^{3}$ and Refaat A Hegazi ${ }^{3^{*}}$

${ }^{1}$ Baylor University Medical Center, Baylor Heart and Vascular Institute, Baylor Jack and Jane Hamilton Heart and Vascular Hospital, Dallas, Texas, USA ${ }^{2}$ The Heart Hospital, Plano, Texas, USA

${ }^{3}$ Scientific and Medical Affairs, Abbott Nutrition (Abbott Laboratories), Columbus, Ohio, USA

\begin{abstract}
The loss of muscle mass and strength is a consequence of the aging process and can occur during periods of bed rest, inactivity, trauma, illness as well. For older adults with advanced heart failure (HF)- associated cachexia, disease-related loss of muscle mass and strength is a complication of the disease state and is associated with deconditioning and frailty. As patients with HF progress, the likelihood of developing malnutrition and cachexia increases. Cachexia is associated with lean body mass (LBM) loss and is correlated with a worsening prognosis in HF. Nutrition interventions beyond simple caloric replacement could be an important adjuvant therapy for a better clinical outcome. Specifically, nutrients that improve the muscle protein synthesis and decrease degradation are of special consideration for the management of cardiac cachexia. Dietary protein intake, oral nutrition supplements and $\beta$-hydroxy $\beta$ - methylbutyrate (HMB) are few examples. $\mathrm{HMB}$ is the active metabolite of the essential amino acid leucine and is found in trace amounts in some foods. It has been shown to inhibit muscle proteolysis and modulate protein turnover. It is also been shown to stabilize muscle cell walls through the production of cholesterol within the muscle tissue. In the following review, we will focus on HMB as a potential nutritional compound that could help address the HF-associated loss of LBM and its consequences.
\end{abstract}

Keywords: Cardiac cachexia; Heart failure; Lean body mass, $\beta-$ hydroxy-- $\beta$-methylbutyrate (HMB)

Many chronic diseases are associated with poor appetite and weight loss. Cachexia is a more complex disorder that encompasses a variety of additional factors including immune, metabolic, and absorption defects. Cachexia can be seen in the patient with heart failure (HF), especially in advanced disease. Addressing nutrition is a necessary focus of management in the patient, and intervening with nutrition to best address the increased lean body mass (LBM) losses seen in these patients may limit the consequences of cardiac cachexia.

\section{Overview of Heart Failure}

HF results from a structural or functional cardiac defect, specifically the ventricles are not able to adequately fill with or eject blood and maintain normal perfusion of vital organs or the systemic circulation [1]. HF affects approximately $10 \%$ of men and $8 \%$ of women over the age of 60 years, and its prevalence rises with advancing age, affecting more than 5.8 million people in the United States [2,3]. Advances in cardiovascular disease interventions, such as hypertension, have improved survival of patients with cardiac disease; however, the cost has been an increased incidence of HF [4]. The five- year survival in $\mathrm{HF}$ is $50 \%$ and at ten years, $90 \%$ of HF patients have succumbed to the disease [5]. Mortality in HF is very cause-specific; meaning that the vast majority of patient with HF die of either pump failure or sudden arrhythmic death. Approximately half of HF cases have reduced and half preserved left ventricular systolic function. Among those with systolic dysfunction, approximately two thirds of cases are due to ischemic cardiomyopathy and prior myocardial infarction. Importantly, cachexia influences the outcomes of all forms of heart failure and appears to be related to neurohormonal activation and elevation of circulating cytokines including tumor necrosis factor alpha. Additionally, cachexia is predisposing factor for the development of type 1 cardiorenal syndrome whereby there is acute decompensation of HF complicated by acute kidney injury [6].
HF is the final stage of cardiac disease, arising from long-standing ischemic disease and contributes to the widespread dysfunction of the body's organ systems, including musculoskeletal, immune, and neuroendocrine systems $[7,8]$. Patients with $\mathrm{HF}$ also experience multiple co-morbidities, such as chronic kidney disease, osteoporosis, anemia, and cachexia, which have been shown to reduce functional capacity [9]. Multiple studies have indicated that functional capacity as measured with cardiopulmonary stress testing is strongly associated with survival. Additionally, exercise training improves functional capacity and has been associated with reductions in HF hospitalizations and death. These benefits extend even to those with deconditioning and obesity where it is possible to have evidence of muscle wasting and cachexia while preserving body fat [10].

\section{HF Associated Loss of Lean Body Mass}

Cardiac cachexia clinically manifests as rapid, unintentional weight loss, profound muscle loss, fatigue, weakness, and anorexia [11]. It is estimated that $12-15 \%$ of people with New York Heart Association (NYHA) classes II-IV have cachexia, which increases as disease severity increases [12]. Cardiac cachexia is an independent risk factor for mortality, as early research showed a 50\% mortality rate at 18 months

*Corresponding author: Refaat A Hegazi, Scientific and Medical Affairs, Abbott Nutrition (Abbott Laboratories), Columbus, Ohio, USA, Tel: 724-2348336; E-mail: refaat.hegazi@abbott.com

Received October 10, 2015; Accepted October 29, 2015; Published November 05, 2015

Citation: McCullough PA, Berberich CB, Alish C, Hegazi RA (2015) The Potentia Role of $\beta-$ Hydroxy- $\beta-$ Methylbutyrate (HMB) in the Management of Lean Body Mass Loss in Older Adults with Heart Failure and Cardiac Cachexia. Cardiovasc Pharm Open Access 4: 161. doi:10.4172/2329-6607.1000161

Copyright: @ 2015 McCullough PA, et al. This is an open-access article distributed under the terms of the Creative Commons Attribution License, which permits unrestricted use, distribution, and reproduction in any medium, provided the original author and source are credited. 
Citation: McCullough PA, Berberich CB, Alish C, Hegazi RA (2015) The Potential Role of $\beta$-Hydroxy- $\beta$-Methylbutyrate (HMB) in the Management of Lean Body Mass Loss in Older Adults with Heart Failure and Cardiac Cachexia. Cardiovasc Pharm Open Access 4: 161. doi:10.4172/23296607.1000161

from initial diagnosis, a rate that is higher than some forms of cancer [13].

Unfortunately, because there is no universally accepted and utilized definition of cachexia, it is rarely identified or diagnosed and therefore not treated. To encourage clinicians to diagnose and treat cachexia, the Cachexia Society defines it as "a complex metabolic syndrome associated with underlying illness and characterized by loss of muscle with or without loss of fat mass" [14]. For adults, the notable clinical feature is unintentional weight loss, defined by the Society as $\geq 5 \%$ in 12 months or less that is adjusted for fluid retention. Fatigue, decreased muscle strength, anorexia, inflammation, and increased muscle protein degradation are additional features or markers of $\mathrm{HF}$ and cardiac cachexia that clinicians should be looking for in their patients, as they are implicated in disease-associated muscle wasting that is cachexia (Figure 1)

Muscle mass makes up a substantial portion of the involuntary or unintentional weight loss that HF patients experience. Older patients with HF lose muscle mass as a consequence of aging, a condition known as sarcopenia. However, the muscle mass and strength losses they incur are also complications of the disease process. Additionally, loss of muscle mass and strength, or sarcopenia, is a consequence of aging. Loss of muscle mass in HF impacts muscle strength, mobility, functional capacity, independence, and quality of life, and increases the risk for negative events such as falls, fractures, infections and medical complications [14-16].

The exact mechanism by which HF promotes cachexia and loss of lean muscle mass is not completely known. Cachexia is thought to occur when there is an imbalance between the catabolic and anabolic processes occurring in the body. In HF, there are several potential pathways of excessive catabolism leading to cardiac cachexia; the production of neurohomones and pro-inflammatory cytokines, specifically tumor necrosis factor alpha which induces apoptosis and muscle protein breakdown [17]. Additionally intestinal wall edema can occur in patients with HF and lead to bacterial translocation which can activate the inflammatory response. Decreased appetite or anorexia, intestinal malabsorption and having higher resting energy expenditure all may be seen in patients with HF and likely play a role in the development and maintenance of a cachectic state [18]. Malnutrition and lean body mass loss are common among heart failure patients and in cardiac cachexia. However, while these both can be reversed with proper nutrition, cachexia does not respond to traditional forms of nutrition intervention [17].

\section{HMB Pharmacodynamics}

HMB ( $\beta$-hydroxy- $\beta$-methylbutyrate) is a metabolite of leucine, a branched-chain essential amino acid consumed from dietary sources [19]. Leucine regulates protein synthesis and helps maintain nitrogen balance, an indicator of the availability of protein for the body's use $[20,21]$. HMB is the active metabolite of leucine that regulates protein synthesis in muscle cells [22]. HMB has been shown to inhibit muscle proteolysis and modulate protein turnover [23-26].

An overview of the leucine-HMB metabolic pathway in mammals is shown in Figure 2. The first step in leucine metabolism is transamination to a-ketoisocaproate (KIC) in muscle cells. KIC is excreted from muscle and transported to the liver. In the liver [19], the majority of KIC is oxidized to isovaleryl coenzyme A (isovaleryl$\mathrm{CoA}$ ) in the mitochondria and ultimately metabolized acetoacetate and acetyl- CoA; approximately $5 \%$ of KIC is metabolized to HMB by KIC-dioxygenase, a cytosolic enzyme; HMB is then released into circulation. In a multistep process, HMB is converted to $\beta$-hydroxy- $\beta$ -
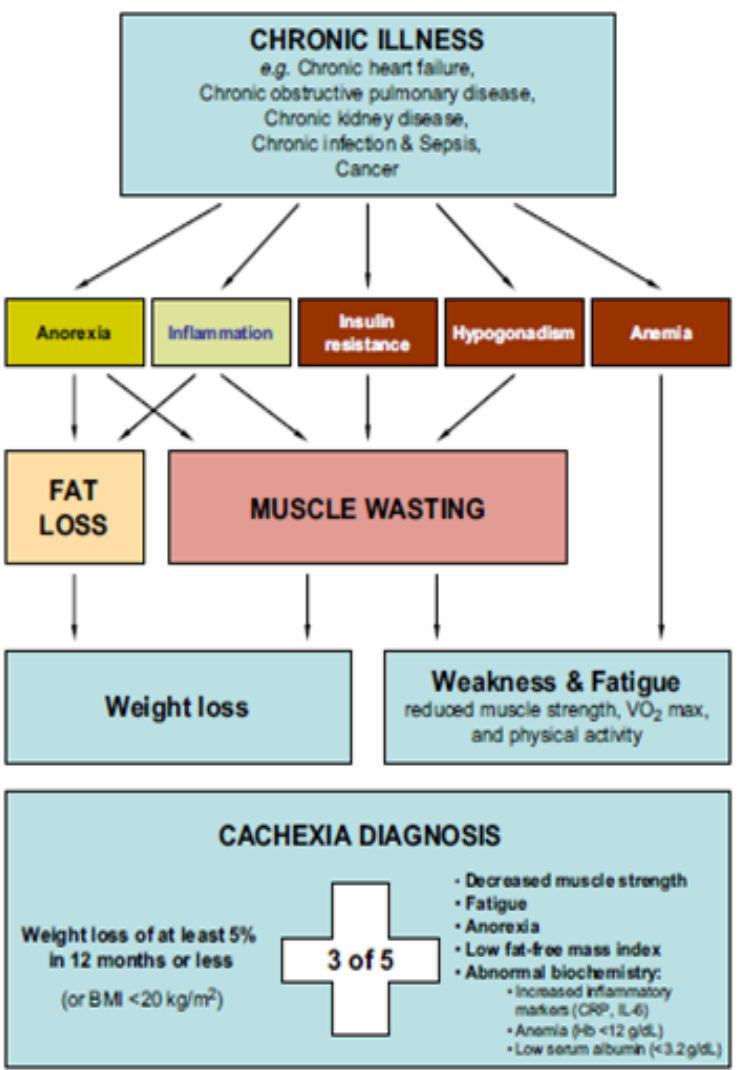

Figure 1: Conceptual model of the definition and clinical diagnosis of cachexia (Cachexia Society).

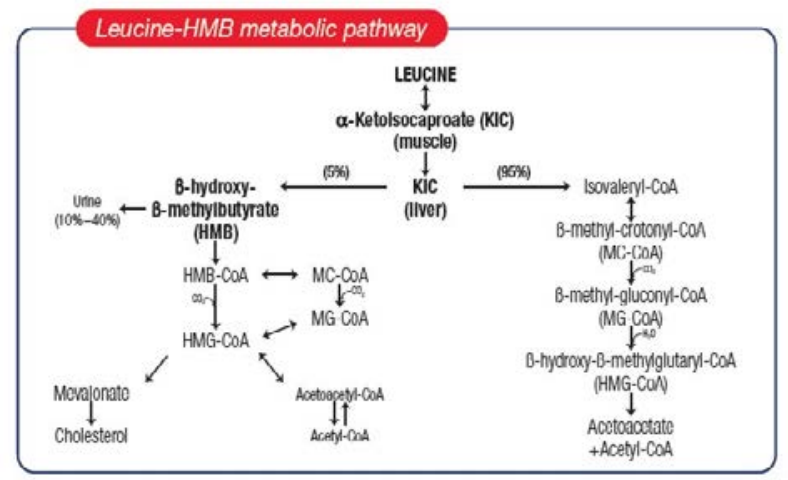

Reprinted with permission from Nissen and Abumrad19

Figure 2: HMB is a leucine metabolite and a precursor of cholesterol synthesis in skeletal muscle.

methylglutaryl- coenzyme A (HMG-CoA) in the cytosol of muscle cells [19]. HMG-CoA is converted to cholesterol. Muscle produces its own cholesterol to maintain the integrity of the cell membrane, typically from HMG-CoA, because it cannot supply its cholesterol needs via absorption from the circulation [19].

The pharmacokinetic profile of exogenous HMB was examined in two randomized controlled studies involving 8 healthy male volunteers. The first study compared the pharmacokinetic disposition of $1 \mathrm{~g}$ CaHMB versus placebo; the second compared $3 \mathrm{~g} \mathrm{CaHMB}$ and $3 \mathrm{~g}$ CaHMB administered with glucose. HMB demonstrated dosedependent kinetics that was altered by glucose co-administration (Table 1) [27]. The results of these two trials showed that peak plasma 
Citation: McCullough PA, Berberich CB, Alish C, Hegazi RA (2015) The Potential Role of $\beta$-Hydroxy- $\beta$-Methylbutyrate (HMB) in the Management of Lean Body Mass Loss in Older Adults with Heart Failure and Cardiac Cachexia. Cardiovasc Pharm Open Access 4: 161. doi:10.4172/23296607.1000161

Page 3 of 5

\begin{tabular}{|c|c|c|c|}
\hline \multicolumn{4}{|c|}{ Dose-dependent pharmacokinetics } \\
\hline $\begin{array}{c}\text { Pharmacokinetic } \\
\text { parameter }\end{array}$ & $1 \mathrm{~g} \mathrm{HMB}$ dose & $3 \mathrm{~g} \mathrm{HMBdose}$ & $\begin{array}{c}3 \mathrm{~g} \mathrm{HMB}+75 \mathrm{~g} \\
\text { glucose }\end{array}$ \\
\hline $\begin{array}{c}\text { Peak plasma } \\
\text { concentration }\end{array}$ & $-120 \mathrm{nmoi} / \mathrm{L}$ & $-480 \mathrm{nmoVL}$ & $-350 \mathrm{nmoVL}$ \\
\hline $\begin{array}{c}\text { Time to } \\
\text { peak plasma } \\
\text { concentration }\end{array}$ & $2.0 \mathrm{hr}$ & $1.0 \mathrm{hr}$ & $1.9 \mathrm{hr}$ \\
\hline $\begin{array}{c}\text { Plasma half-life } \\
\text { \%Accumulation in } \\
\text { urine }\end{array}$ & $2.37 \mathrm{hr}$ & $2.38 \mathrm{hr}$ & $2.59 \mathrm{hr}$ \\
\hline
\end{tabular}

Table 1: Exogenous HMB pharmacokinetics profile27.

concentrations occurred more quickly after larger HMB doses, but the difference in plasma half-life was minimal. In addition, ingestion of HMB with glucose lowered the peak plasma concentration and time to peak plasma concentration, and increased HMB half-life. Intake of HMB increases plasma HMB levels and causes the plasma concentration to peak between 1 and 2 hours. The half- life was approximately 2.3 hours. Previous studies have shown that approximately $10 \%$ to $40 \%$ of HMB is excreted in urine [19]; in this study, approximately $71 \%$ to $86 \%$ of an HMB dose remained in the body following the $3 \mathrm{~g}$ or $1 \mathrm{~g}$ dose, respectively [27].

Exogenous HMB may also serve as a precursor for cellular cholesterol in muscle and contribute to cell membrane stabilization. This de novo synthesis in this case is restricted to local use, based on the lack of increase in circulating cholesterol with supplemental HMB [28]. Tumor necrosis factor alpha, interferon gamma, angiotensin II, and lipopolysaccharide each can activate caspase- 8 , a protein in the cell membrane that activates another protein within the cell, caspase-3. Interaction between caspase- 3 and an intracellular protein reduces protein synthesis in the nucleus. HMB inhibits the activation of caspase-8, thereby [29-31] preventing the downregulation of protein synthesis and increasing inhibition of protein degradation initiated by nuclear factor kappa B (NFkB). Thus, by inhibiting caspase- 8 activation on the cell membrane, HMB maintains protein synthesis and prevents additional protein degradation. In cancer, PIF activates arachidonic acid in the muscle cell membrane, leading to the subsequent production of inflammatory mediators within the cell cytoplasm. An interaction between these inflammatory mediators and intracellular proteins activates NFKB. HMB interrupts the interaction between an arachidonic acid product and intracellular protein to prevent the NFKB activation, thereby attenuating the upregulation of protein degradation [29-31].

\section{Evidence of HMB}

Traditionally HMB has been used by athletes to enhance performance and build muscle mass [32]. Research has focused on the use of HMB to preserve or rebuild muscle mass in populations in whom loss LBM would increase risk for injury, disability, or mortality. There are more than 70 citations of HMB research on the benefits of HMB supplementation, either alone or in combination with amino acids in rebuilding LBM in adults 65 years of age and older, as well as in people with chronic diseases such as AIDS and cancer [33-36]. Studies in animals and in humans suggest that HMB increases protein synthesis and decreases protein degradation. In studies where various kinds of stress were induced in animals, HMB supplementation increased muscle mass. In clinical studies of people who are exercising, HMB has been shown to increase muscle mass. In older adults, studies with HMB supplementation, with or without exercise, have shown positive effects on strength and functionality [33,34,37-39].

A randomized, placebo controlled study compared the effects of
HMB supplementation, as 3grams of calcium HMB (CaHMB), on muscle mass and strength in healthy older adults volunteers confined to complete bed rest for ten days. The results of the study demonstrated that bed rest caused a significant reduction in total lean body mass in the control group ( $\mathrm{p}=0.02)$, compared to the treatment group who experienced non-significant loss of muscle mass $(p=0.23)$. There was no significant difference in muscle strength between groups, likely resulting from the small sample sizes. This study demonstrated that supplementation with CaHMB in healthy older adults preserved muscle mass during bed rest [37].

A previous randomized controlled trial by Vukovich, et al. also showed that HMB can have a positive effect on strength and fat free mass in older adults [33]. Over an 8-week study period, subjects who were randomized to consume $3 \mathrm{~g}$ of CaHMB per day had an increase in fat-free mass gain versus the placebo group $(p=0.08)$ [33]. In addition, HMB supplementation increased the percentage of body fat loss $(\mathrm{p}=0.05)$ and a greater decrease in the percentage of body fat compared to the placebo group $(p<0.05)$ [33]. These studies have shown that the effective dose of CaHMB is $3 \mathrm{~g}$ per day in various population groups.

Stout et al. compared the effects of 24 weeks of daily supplementation of $3 \mathrm{~g}$ of $\mathrm{CaHMB}$ supplementation on lower extremity muscle strength in non-exercising, healthy adults, 65 years of age and older. At 24 weeks, there was a significant improvement in lower extremity muscle strength and muscle quality, compared to the placebo group $(\mathrm{p}<0.05)$ [38].

Wu et al. recently conducted a systematic review and meta-analysis of the effect of HMB supplementation on muscle loss and muscle strength and performance in older adults. Seven studies meeting their criterial were included, in which 147 adults received CaHMB in doses of 2 to 3 grams per day, and 140 participants received placebo. The results of the meta-analysis showed significant improvements in muscle mass gains with HMB supplementation, compared to placebo $(\mathrm{p}=0.004)$, without significant gains in fat mass. Due to variability in strength measures and physical performance tests, a meta-analysis could not be performed. The authors concluded that HMB supplementation contributes to muscle mass preservation in aging adults [39].

\section{The Potential Role of HMB in Patients with Cardiac Cachexia}

As mentioned previously, the prevalence of cachexia in patients with HF is significant and increases as the disease state worsens. Since cachexia is an independent risk factor for mortality, adequately addressing its presence becomes important in the management of HF. HMB may play a role in mitigating cardiac cachexia by limiting the degradation of lean body mass. Cachexia can cause an increase of inflammatory mediators leading to increased muscle degradation but it has negative impacts on cardiac tissue as well. HMB can potentially impact HF-induced cachexia by limiting the protein breakdown in the skeletal muscles, thus maintaining lean body muscle mass.

$\mathrm{HMB}$ can support the integrity of muscle cell walls thorough the local, de novo synthesis of cholesterol. HMB may also limit the detrimental effects of cachexia through potentially limiting the catabolic effects of cytokines on muscle protein synthesis. In many chronic disease states, including HF, there are higher levels of circulating cytokines such as TNF- $\alpha$ and angiotensin 11 [29]. One of the many effects of these cytokines is upregulating protein degradation within the muscle cell. HMB inhibits this process allowing the muscle cell proteins to be preserved. As patients with HF progress, reducing the effects of cachexia becomes all the more important as it is a predictive factor for survival [12]. The impact of HMB on muscle outcomes in HF 
Citation: McCullough PA, Berberich CB, Alish C, Hegazi RA (2015) The Potential Role of $\beta$-Hydroxy- $\beta$-Methylbutyrate (HMB) in the Management of Lean Body Mass Loss in Older Adults with Heart Failure and Cardiac Cachexia. Cardiovasc Pharm Open Access 4: 161. doi:10.4172/23296607.1000161

Page 4 of 5

patients is yet to be explored and deserves consideration. HMB is wellstudied in a variety of patients experiencing severe muscle loss, such as in HIV and cancer cachexia. Specifically, in a study of AIDS-associated wasting, oral supplementation with the combination of $\mathrm{HMB}$, arginine, and glutamine increased muscle mass acquisition and body weight, in addition to increasing CD3 and CD8 counts [35]. Therefore it is not unreasonable to surmise that HMB could provide some clinical benefit for patients with cardiac cachexia, a hypothesis that warrants clinical investigation.

The main focus of cachexia treatment is nutritional therapy, however as it is much more complex disorder than simple undernourishment, the type of nutrition matters as well as the use other methods of therapy such as physical activity and medication use [12]. The use of supplemental HMB in combination with adequate macro and micronutrients can potentially limit the effects of cachexia by preserving lean body mass. Preserving lean body muscle mass in patients with HF is important since regular physical activity can slow the progression of this disease.

\section{Conclusion}

Heart Failure is a complex, progressive disorder that can induce a cachectic state in afflicted individuals. Cachexia in patients with HF is associated with significant losses in lean body mass and has a negative impact on survival. $\beta$-hydroxy- $\beta$-methylbutyrate is a metabolite of the essential amino acid leucine and has been shown in multiple clinical studies to impact muscle tissue by stabilizing muscle cell walls and down regulating intracellular protein breakdown. Maintaining lean body mass and limiting the effects of cachexia is a vital part of slowing the progression of this disease. Due to these factors, HMB may play a role in the nutritional management in patients experiencing HFinduced cachexia.

\section{References}

1. Hunt SA, et al. (2009) 2009 Focused update incorporated into the ACC/AHA 2005 Guidelines for the Diagnosis and Management of Heart Failure in Adults A Report of the American College of Cardiology Foundation/American Heart Association Task Force on Practice Guidelines Developed in Collaboration With the International Society for Heart and Lung Transplantation. J Am Coll Cardiol 53: e1-e90

2. Braunwald E (2013) Heart failure. JACC Heart Fail 1: 1-20

3. Go AS, Mozaffarian D, Roger VL, Benjamin EJ, Berry JD, et al. (2014) Heart disease and stroke statistics--2014 update: a report from the American Heart Association. Circulation. 129(3): e28- e292.

4. Bourdel-Marchasson I, Emeriau JP (2001) Nutritional strategy in the management of heart failure in adults. Am J Cardiovasc Drugs 1: 363-373.

5. McCullough PA, Philbin EF, Spertus JA, Kaatz S, Sandberg KR, et al. (2002) Confirmation of a heart failure epidemic: findings from the Resource Utilization Among Congestive Heart Failure (REACH) study. J Am Coll Cardiol 39: 60-69.

6. Ronco C, Cicoira M, McCullough PA (2012) Cardiorenal syndrome type 1 pathophysiological crosstalk leading to combined heart and kidney dysfunction in the setting of acutely decompensated heart failure. J Am Coll Cardiol 60(12): 1031-42.

7. Anker SD, von Haehling S (2004) Inflammatory mediators in heart failure: an overview. Heart 90: 464-70.

8. Jankowska EA, Biel B, Majda J, Szklarska A, Lopuszanska M, et al. (2006) Anabolic deficiency in men with chronic heart failure: prevalence and detrimental impact on survival. Circulation 114: 1829-1837.

9. Fulster S, Tacke M, Sandek A, Ebner N, Tschöpe C, et al. (2013) Muscle wasting in patients with heart failure: results from the studies investigating comorbidities aggravating heart failure (SICA-HF). Eur Heart J 34: 512-9.

10. Horwich TB, Broderick S, Chen L, McCullough PA, Strzelczyk T, et al. (2011) Relation among body mass index, exercise training, and outcomes in chronic systolic heart failure. Am J Cardiol 108: 1754-1759.

11. Azhar G, Wei JY1 (2013) New Approaches to Treating Cardiac Cachexia in the
Older Patient. Curr Cardiovasc Risk Rep 7: 480-484

12. Pureza V, Florea VG (2013) Mechanisms for cachexia in heart failure. Curr Heart Fail Rep 10: 307-314.

13. Anker SD, Ponikowski P, Varney S, Chua TP, Clark AL, et al. (1997) Wasting as independent risk factor for mortality in chronic heart failure. Lancet 349 : 1050-1053.

14. 14. Evans WJ, Morley JE, Argilés J, Bales C, Baracos V, et al. (2008) Cachexia: a new definition. Clin Nutr 27: 793-799.

15. Jennekens, FGI (1992) Disuse, cachexia and ageing. In: Mastaglia FL and Walton JN (eds) Skeletal muscle pathology. Churchill Livingstone, London.

16. Demling RH (2009) Nutrition, anabolism, and the wound healing process: an overview. Eplasty 9: e9.

17. Akashi YJ, Springer J, Anker SD (2005) Cachexia in chronic heart failure: prognostic implications and novel therapeutic approaches. Curr Heart Fail Rep 2: 198-203.

18. Von Haehling S, Doehner W, Anker SD (2007) Nutrition, metabolism, and the complex pathophysiology of cachexia in chronic heart failure. Cardiovasc Res 73: 298-309.

19. Nissen SL, Abumrad NN (1997) Nutritional role of the leucine metabolite $\beta$-hydroxy $\beta$ - methylbutyrate (HMB). J Nutr Biochem 8:300-311.

20. Williams JZ, Barbul A (2003) Nutrition and wound healing. Surg Clin North Am 83: 571-596.

21. May ME, Buse MG (1989) Effects of branched-chain amino acids on protein turnover. Diabetes Metab Rev 5: 227-245.

22. Manzano M, Giron MD, Salto R, Sevillano N, Rueda R, et al. (2009) Is $\beta$ -hydroxy- $\beta$ - methylbutyrate (HMB) the bioactive metabolite of L-leucine (LEU) in muscle? Molecular evidence and potential implications.

23. Alon T, Bagchi D, Preuss HG (2002) Supplementing with beta-hydroxy-betamethylbutyrate (HMB) to build and maintain muscle mass: a review. Res Commun Mol Pathol Pharmacol 111: 139-151

24. Nissen S, Sharp R, Ray M, Rathmacher JA, Rice D, et al. (1996) Effect of leucine metabolite beta-hydroxy-beta-methylbutyrate on muscle metabolism during resistance-exercise training. J Appl Physiol (1985) 81: 2095-2104.

25. Smith HJ, Mukerji P, Tisdale MJ (2005) Attenuation of proteasome-induced proteolysis in skeletal muscle by \{beta\}-hydroxy-\{beta\}-methylbutyrate in cancer-induced muscle loss. Cancer Res 65: 277-283.

26. Smith HJ, Wyke SM, Tisdale MJ (2004) Mechanism of the attenuation of proteolysis-inducing factor stimulated protein degradation in muscle by betahydroxy-beta-methylbutyrate. Cancer Res 64: 8731-8735.

27. Vukovich MD, Slater G, Macchi MB, Turner MJ, Fallon K, et al. (2001) betahydroxy-beta-methylbutyrate $(\mathrm{HMB})$ kinetics and the influence of glucose ingestion in humans. J Nutr Biochem 12: 631-639.

28. Nissen S, Sharp RL, Panton L, Vukovich M, Trappe S, et al. (2000) betahydroxy-beta-methylbutyrate (HMB) supplementation in humans is safe and may decrease cardiovascular risk factors. J Nutr 130: 1937-1945.

29. Eley HL, Russell ST, Tisdale MJ (2008) Attenuation of depression of muscle protein synthesis induced by lipopolysaccharide, tumor necrosis factor, and angiotensin II by $\beta$-hydroxy- $\beta$ - methylbutyrate. Am JPhysiol Endocrinol Metab 295: E1409-E1416.

30. Eley HL, Russell ST, Tisdale MJ (2008) Mechanism of attenuation of muscle protein degradation induced by tumor necrosis factor-a and angiotensin II by $\beta$-hydroxy- $\beta$-methylbutyrate. Am J Physiol Endocrinol Metab 295: E1417-E1426

31. Eley HL, Russell ST, Baxter JH, Mukerji P, Tisdale MJ (2007) Signaling pathways initiated by beta-hydroxy-beta-methylbutyrate to attenuate the depression of protein synthesis in skeletal muscle in response to cachectic stimuli. Am J Physiol Endocrinol Metab 293: E923-931.

32. Wilson GJ, Wilson JM, Manninen AH (2008) Effects of beta-hydroxy-betamethylbutyrate (HMB) on exercise performance and body composition across varying levels of age, sex, and training experience: A review. Nutr Metab (Lond) 5: 1.

33. Vukovich MD, Stubbs NB, Bohlken RM (2001) Body composition in 70-year-old adults responds to dietary beta-hydroxy-beta-methylbutyrate similarly to that of young adults. J Nutr 131: 2049-2052. 
Citation: McCullough PA, Berberich CB, Alish C, Hegazi RA (2015) The Potential Role of $\beta$-Hydroxy- $\beta$-Methylbutyrate (HMB) in the Management of Lean Body Mass Loss in Older Adults with Heart Failure and Cardiac Cachexia. Cardiovasc Pharm Open Access 4: 161. doi:10.4172/23296607.1000161

34. Flakoll P, Sharp R, Baier S, Levenhagen D, Carr C, et al. (2004) Effect of $\beta$-hydroxy- $\beta$ - methylbutyrate, arginine, and lysine supplementation on strength, functionality, body composition, and protein metabolism in elderly women. Nutrition 20: 445-451.

35. Clark RH, Feleke G, Din M, et al. (2000) Nutritional treatment for acquired immunodeficiency virus-associated wasting using ß-hydroxy ß-methybutyrate, glutamine, and arginine: a randomised, double-blind, placebo controlled study. JPEN J Parenter Enteral Nutr 24: 133-139.

36. May PE, Barber A, D'Olimpio JT, Hourihane A, Abumrad NN (2002) Reversal of cancer-related wasting using oral supplementation with a combination of beta-hydroxy-beta-methylbutyrate, arginine, and glutamine. Am J Surg 183 471-479.
37. Deutz NE, Pereira SL, Hays NP, Oliver JS, Edens NK, et al. (2013) Effect of $\beta$-hydroxy- $\beta$-methylbutyrate (HMB) on lean body mass during 10 days of bed rest in older adults. Clin Nutr 32: 704-712.

38. Stout JR, Smith-Ryan AE, Fukuda DH, Kendall KL, Moon JR, et al. (2013) Effect of calcium $\beta$-hydroxy- $\beta$-methylbutyrate (CaHMB) with and without resistance training in men and women $65+y$ rs: a randomized, double-blind pilot trial. Exp Gerontol 48: 1303-1310.

39. Wu H, Xia Y, Jiang J, Du H, Guo X, et al. (2015) Effect of beta-hydroxy-betamethylbutyrate supplementation on muscle loss in older adults: a systematic review and meta-analysis. Arch Gerontol Geriatr 61: 168-175. 